\title{
Elektriklenme, Yıldırım Ve Şimşek İle İlgili Öğrenci Zihinsel Modellerinin İncelenmesi
}

\author{
Mehmet Altan KURNAZ \\ Fatma TARAKÇ ${ }^{* *}$ \\ Abdullah AYDIN*** \\ Murat PEKTAŞ
}

Özet

$\mathrm{Bu}$ araştırmanın amacı ortaöğretim öğrencilerinin elektriklenme, yıldırım ve şimşek kavramlarıyla ilgili zihinsel modellerini tespit etmektir. Araştırma kapsamında özel durum araştırma yöntemi benimsenmiştir. Araştırma 2012-2013 akademik yılında bir il merkezindeki liselerde öğrenim gören ve amaçlı örnekleme yöntemiyle seçilmiş 110 öğrenci ile yürütülmüştür. Öğrencilerin zihinsel modellerini tespit etmek üzere betimleme ve görsellemeyi gerektiren toplam altı açı uçlu sorudan yararlanılmıştır. Analizler betimleme ve görselleme durumlarının karşılaştırılması ve ilkel, sentez ve bilimsel modeller şeklinde sınıflandırması yoluyla gerçekleştirilmiştir. Analizler sonucunda, öğrenci zihinsel modellerinin dağılımının sentez modellerde çoğunluk gösterdiği tespit edilmiştir.

Anahtar kelimeler: Zihinsel model, yıldırım, şimşek, elektriklenme.

\section{An Analysis Of High School Students' Mental Models Of Electrification, Thunder And Lightning}

\footnotetext{
Abstract

The aim of this study was to examine high school students' mental models of electrification, thunder and lightning. Within this research, a case

*Yrd. Doç. Dr., Kastamonu Üniversitesi Eğitim Fakültesi İlköğretim Bölümü, Kastamonu. E-mail: altan.kurnaz@gmail.com; makurnaz@kastamonu.edu.tr

${ }^{* *}$ Kastamonu Üniversitesi Fen Bilimleri Enstitüsü Yüksek Lisans Öğrencisi, Kastamonu

${ }^{* * *}$ Doç. Dr., Kastamonu Üniversitesi Eğitim Fakültesi İlköğretim Bölümü,

Kastamonu

**** Yrd. Doç. Dr., Kastamonu Üniversitesi Eğitim Fakültesi İlköğretim Bölümü, Kastamonu
} 
study was carried out. The study was carried out with 110 students and study group was selected with purposeful sampling method in the academic year of 2012-2013in one of city of Turkey. In order to identify students' mental models of a total of six open-ended questions those require description and visualization utilized. Analysis was carried out by comparing the description and visualization answers of students, and mental models of students were elicited by means of classification as primitive, synthesis and scientific models. As a result of analysis, synthesis models were determined the mental model of majority of the students.

Key words: Mental models, electrification, thunder, lightning.

\section{Giriş}

Öğrenme sürecine ilişkin güncel yaklaşımlar, öğrenmenin basit bir süreç olmadığını, formal ve informal ortamlarda gerçekleşebileceğini ve sürecinin merkezinde öğrenenin olduğunu vurgulamaktadır. Buradan da anlaşılacağ gibi, öğrencilerin formal öğrenme ortamına informal öğrenme ortamlarından edindikleri bilgilerle geldiği ifade edilebilir. Bu durum günümüzde artık bilinen ve kabul edilen bir gerçeklik olup Ausebel'in öğrenmeye dair görüşlerine göre öğrenme sürecini doğrudan etkilemektedir. Yani bir ders kapsamında edinilen bilgiler, ön bilgilerin üzerine inşa edilmektedir.

Öğrencilerin öğrenme ortamına bilgi doldurulmaya gelen sade bireyler olarak düşünülmemesi gerektiği açıtır (Özmen, Demircioğlu \& Coll, 2009). Gerçekte öğrencilerin kritik eden ve yapılandıran aktif bireyler olarak dikkate alınması gerekmektedir. Yani öğrenci ön bilgilerinin bilimsel anlamla örtüşmeme durumu söz konusu olduğundan (Çalık \& Ayas, 2005) anlamlı/derinlemesine öğrenmelerin gerçekleştirilebilmesi için öğretmenler konuyla ilgili öğrenci ön bilgilerini önceden bilmek durumundadır. Ulusal literatürümüzde bu gerekçeyi dikkate alarak gerçekleştirilen pek çok çalışmada, 'kavram yanılgıları', 'öğrenci alternatif fikirleri' gibi farklı adlar altında öğrencilerin ön bilgilerinin incelendiği/belirlendiği dikkat çekmektedir. Kuvvet ve hareket (Keleş, 2007; Yürük, 2007), kütle ve ağırlık (Koray, Özdemir \& Tatar, 2005), 1sı ve sıcaklık (Aydoğan, Gümüş \& Gülçiçek, 2007; Buluş \& Güllü, 2008), 1şık (Büyükkasap, Düzgün \& Ertuğrul, 2001), elektrik akımı (Sencar, Yılmaz, \& Eryılmaz, 2001) konularıyla ilgili yapılan çalışmalar örnek olarak verilebilir. 
Öğrenmeye dair güncel bakış açılarından biri de Model Tabanlı Öğrenme (MTÖ) yaklaşımı (Gobert \& Buckley, 2000; Buckley vd., 2002; Hanke, 2008) olup bu yaklaşım bir bilgiye/olguya dair zihinsel model yapılandırıldığı fikrini temel almaktadır (Nersessian, 1995; Gobert \& Buckley, 2000). Buna göre bireyler karşılaştıkları durum veya olaylar için zihinsel model yapılandırmasına gitmektedirler (Driver, 1995; Duit \& Treagust, 1998; Taylor, Barker \& Jones, 2003). Zihinsel modeller bireylerin gerçek ve soyut dünyayı deneyleme ve anlamlandırmada etkendirler (Hestenes, 2006). Aslında bireyler zihinsel modelleri öncül zihinsel modellerle ilişkilendirerek yapılandırırlar ve bu durum öğrenmeyle zihinsel model yapılandırma ilişkisini yansıtır (Greca \& Moreira, 2002). Yani bir bilgiyi öğrenme süreci o bilgiye dair zihinsel model yapılandırmayı içerir (Hanke, 2008; Hanke \& Huber, 2010).

Yukarıda çizilen çerçeveden hareketle biz eğitimcilerin öncelikli görevlerinden birisinin de öğrencilerin ön bilgilerini belirlemek olduğu kadar onların zihinsel modellerini de tespit etmek olduğu söylenebilir. Böylelikle öğretmenlere öğrenme ortamlarını tasarlama ve/veya geliştirmede yararlı bilgiler sunulabilir. Bu anlamda elektriklenme, yıldırım ve şimşek kavramlarıyla ilgili öğrenci zihinsel modelleri çalışmanın odağını oluşturmaktadır.

Elektrik konusu fizik müfredatlarının önemli konularından biri olmasına rağmen (Ateş, 2005; Borges \& Gilbert, 1999), elektriklenme, yıldırım ve şimşek kavramlarıyla ilgili literatürde yeterince çalışmaya rastlanmamaktadır. Bu anlamda iki çalışma dikkat çekmektedir. Bunlardan birincisi, yıldırım kavramının farklı yaş gruplarındaki öğrencilerde gelişimini konu almaktadır (Ayvacı, Özsevgeç \& Cerrah, 2004). Ayvacı ve diğ. tarafından yürütülen çalışma, okul öncesinden üniversiteye toplam 80 öğrenciyi kapsayan bir çalışma olup öğrencilerin yıldırım kavramıyla ilgili eksik ve/veya yanlış bilgilerinin olduğunu ortaya koymuştur. İkinci çalışma atmosferde meydana gelen doğal elektriklenme konusundaki öğrenci kavram yanılgılarını konu almaktadır (Aydın \& Özkara, 2011). 127 fen bilgisi öğretmen adayılla yürütülen bu çalışmada, adayların atmosferde meydana gelen doğal elektriklenme konusunda bazı kavram yanılgıları ve bilgi eksikliklerinin olduğu sonucuna varılmıştır. Anlaşıldığ gibi, ulusal literatürümüzde atmosferdeki elektriklenme sonucunda oluşan yıldırım ve şimşek kavramlarının, farklı öğretim kademelerinde öğrenim gören 
öğrencilerin zihinlerinde ne şekilde ve nasıl modellendiğini inceleyen bir çalı̧̧maya rastlanılmamıştır. Bu çerçevede elde edilecek bulguların yapılmış çalışmalara güncel bir alternatif olacağı ve sonraki çalışmalara ışık tutacağı düşünülmektedir.

\section{Amaç}

$\mathrm{Bu}$ çalışmanın amacı, ortaöğretim öğrencilerinin elektriklenme, yıldırım ve şimşek kavramlarıyla ilgili zihinsel modellerini ortaya çıarmaktır.

\section{Yöntem}

Çalışma kapsamında öğrenci zihinsel modelleri incelendiğinden çalışmada betimsel yaklaşım benimsenmiştir. İncelenen durumu detaylıca açıklama, tanımlama, olduğu gibi değerlendirme ve olaylar veya durumlar arasındaki ilişkileri ortaya çıkarmada betimleme çalışmaları etkin olarak tanımlanmaktadır (Çepni, 2012). Bu çalışmada özel durum çalışması araştırma yöntemi olarak kullanılmıştır. Bu yöntem incelenen durumu var olduğu şekliyle inceleme olanağı sunan bir araştırma yöntemi olarak bilinmektedir (Yin, 2003). Bu çalı̧̧madaki özel durum, ortaöğretim öğrencilerinin elektriklenme, yıldırım ve şimşek kavramlarıyla ilgili zihinsel modelleridir. Çalı̧̧mada ortaya çıarılan zihinsel modeller yöneltilen sorulara verilen cevaplarla sinırlıdır.

\section{Çalışma Grubu}

Araştırmanın çalışma grubunu, 2012-2013 akademik yılında bir il merkezindeki liselerde öğrenim gören ve amaçlı örnekleme yöntemiyle seçilmiş 110 (22 dokuzuncu sınıf, 28 onuncu sinıf, 42 on birinci sinıf ve 18 on ikinci sınıf) öğrenci oluşturmaktadır. Konuyla ilgili yürütülen çalışmalarda ortaöğretim seviyesinin henüz yeterince irdelenmemiş olması çalışmanın gerekliliğini ve ulaşılacak sonuçların anlamlılığını farklı bir açıdan tekrar ortaya koymaktadır.

\section{Veri Toplama Aracı}

Zihinsel modellerin ortaya çıkarılmasında hedef kavramla ilgili öğrencilerin teorik ve pratik bilgilerine yönelik sorulardan yola çıkılmalıdır (Kurnaz, 2011). Bu çalışma, öğrencilerin elektriklenme, yıldırım ve şimşek kavramlarıyla ilgili teorik bilgileriyle ilişkili olarak sorulan 6 açık uçlu soru temelinde sinırlandırılarak yürütülmüştür. Sorular zihinsel modellerin ortaya çıkarılmasını konu alan çalışmalarda veri toplama amaçlı sorulan 
sorular ve uzman görüşleri dikkate alınarak hazırlanmıştır. Ayrıca hazırlanan soruların okunabilirliği ve anlaşılabilirliği 15 öğrenciyle yapılan pilot bir uygulamayla test edilmiştir. İlgili sorular aşağıda verilmiştir:

1. Şimşek nedir? Açıklayınız.

2. Şimşek çakması sürecinde meydan gelen etkileşimle ilgili olarak zihninizde oluşan görseli/görselleri çiziniz.

3. Yıldırım nedir? Açılayınız.

4. Yıldırım düşmesi sürecinde meydana gelen etkileşimle ilgili olarak zihninizde oluşan görseli/görselleri çiziniz.

5. Elektriklenme nedir? Açıklayınız.

6. Elektriklenme sürecindeki etkileşime dair zihninizdeki görseli çiziniz.

\section{Veri analizi}

Veri analizi sürecinde öğrencilerin hedef kavramları betimleme ve görselleme durumlarıyla ilgili algıları sorular temelinde belirlenmiştir. $\mathrm{Bu}$ anlamda öğrenci cevapları için 'bilimsel içerikli' ve 'bilimsel içerikli olmayan içeriğe sahip' şeklinde değerlendirme yapılmıştır. Ulaşılan bulguların karşılaştırılmasından hareketle zihinsel modeller belirlenmiştir. Zihinsel model belirleme sürecinde Vosniadou ve Brewer $(1992,1994)$ tarafından önerilen zihinsel modellerden yararlanılmıştır. Bu modeller ilkel, sentez ve bilimsel modellerdir. İlkel model, bilimsel bilgilerle örtüşmeyen cevaplar veren öğrencileri içermektedir. Bu modelde değerlendirilen öğrenciler hedef kavramlarla ilgili okul bilgisinden uzaktırlar. Sentez model, bilimsel bilgilerle kısmen örtüşen veya örtüşmeyen cevaplar veren öğrencileri içermektedir. $\mathrm{Bu}$ modelde sınıflandırılan öğrenciler okul bilgisini kısmen edinmiş olmalarına rağmen bilimsel olmayan bilgilere de sahiptirler. Bilimsel model, hedef kavramlarla ilgili bilimsel cevaplar veren öğrencileri içermektedir. Bu modele sahip öğrenciler okul bilgisine sahiptirler. Analizlerin son aşamasında ise elektriklenme, yıldırım ve şimşek kavramları için ayrı ayrı belirlenen zihinsel modellerin karşılaştırılmasından hareketle konuyla ilgili genel zihinsel modelleri belirlenmiştir.

\section{Bulgular}

Çalışmadan elde edilen bulgular okunabilirliği artırmak için hedef kavramlar temelinde ayrı ayrı sunulmuştur.

Öğrencilerin Şimşekle İlgili Başarı Durumları ve Zihinsel Modelleri 
Öğrencilerin şimşek kavramıyla ilgili algılamalarına yönelik elde edilen bulgular (veri toplama aracının ilk sorusu doğrultusunda) Tablo 1'de sunulmuştur.

Tablo 1: Şimşek Kavramı İçin Betimsel Öğrenci Cevapları Değerlendirmesi

\begin{tabular}{|l|l|l|l|l|l|l|}
\hline \multirow{2}{*}{ Kodlar } & \multicolumn{6}{|l|}{ Sinıflar (f) } \\
\cline { 2 - 8 } & $\mathbf{9}$ & $\mathbf{1 0}$ & $\mathbf{1 1}$ & $\mathbf{1 2}$ & Toplam & \% \\
\hline Bilimsel Doğru & 4 & 3 & 4 & 1 & 12 & 10,91 \\
\hline $\begin{array}{l}\text { Kismen Doğru } \\
\text { (Yanlışsız) }\end{array}$ & 11 & 17 & 25 & 12 & 65 & 59,09 \\
\hline $\begin{array}{l}\text { Kısmen Doğru } \\
\text { Yanlışlı) }\end{array}$ & 4 & 2 & 6 & 1 & 13 & 11,82 \\
\hline Yanlış & 2 & 4 & 5 & 3 & 14 & 12,73 \\
\hline Cevapsız & 1 & 2 & 2 & 1 & 6 & 5,45 \\
\hline
\end{tabular}

Tablo 1'de görüldüğü gibi şimşeğin ne olduğuyla ilgili öğrenci cevaplarının yarıdan fazlası (yaklaşık \% 59) kısmen doğru (yanlışsız) içeriğe/içeriklere sahiptir. Bu kategoride değerlendirilen bazı öğrencilere ait örnek cevaplar "bulutların çarpışması sonucu oluşan doğa olayı (Ö20)" ve "iki bulutun sürtünmesi (Ö43)" şeklindedir. Öğrencilerin yaklaşık \% 11'lik kısmı kısmen doğru (yanlışlı) içeriğe/içeriklere sahip cevaplar vermişlerdir. $\mathrm{Bu}$ kısma ait örnek öğrenci cevapları "gökyüzündeki bulutların zıt yüklerinin birbiri ile birleşmesi sonucu yeryüzüne inen yüksek sesli bir gök olayı (Ö34)" ve "bir bulutun taban ile yer arasında iki bulut arasında veya bir bulut içinde elektrik boşalırken oluşan kırık çizgi (Ö57)" şeklindedir. Bu soruya verilen cevaplar incelendiğinde doğru içeriğe sahip öğrenci cevapları en az orana (yaklaşık \% 10) sahiptir. Buradaki bazı öğrenci örnek cevapları ise "negatif ve pozitif yüklü bulutların birbirleriyle çarpışması sonucu ortaya ses ve görüntünün meydana gelmesi (Ö1)", "yüklü bulutların birbirine sürtünmesiyle oluşan 1şık (Ö44)", "elektrik yüklü bulutların birbirleriyle etkileşmesi sonucu oluşan ışık ve ses olayıdır (Ö67)" ve "karşıt yüklü bulutların çarpışmasıyla ortaya çıkan 1şık (Ö98)" şeklindedir.

Öğrencilerin şimşek çakması sürecinde meydan gelen etkileşimle ilgili olarak zihinlerinde oluşan görseller ile ilgili elde edilen bulgular (veri toplama aracının ikinci sorusu doğrultusunda) Tablo 2'de sunulmuştur. Tablo 2'de yer alan öğrenci çizimlerinin kategorilerine dair açıklamalar aşağıda sunulmuştur: 
Zig zag çizim; bulutlar arasında ya da bulut ile yer arasında, sağa ve sola doğru çizilen düz çizgilerin birleştirilmesi sonucu oluşan görüntüdür.

Düz çizim; bulutlar arasında ya da bulut ile yer arasında, bir doğru boyunca oluşturulan düzlemdir.

Çarşaf çizim; bulutlar arasını ya da bulut ile yer arasını, bir bütün olarak kaplayan ya da iki zig zag çizgi uçlarının birleştirilmesi ile oluşan geniş şekillerdir.

Çatallanmış çizim; bulutlar arasında ya da bulut ile yer arasında, düz çizgilerden veya zig zag çizgilerden dallanan birçok kısa uzantıdır.

Sarmal çizim; bulutlar arasında ya da bulut ile yer arasında, yay şeklindeki kıvrımlı çizimlerdir.

Tablo 2: Şimşek Çakması Sürecinde Meydan Gelen Etkileşimle İlgili Öğrenci Çizimlerinin Nitelikleri

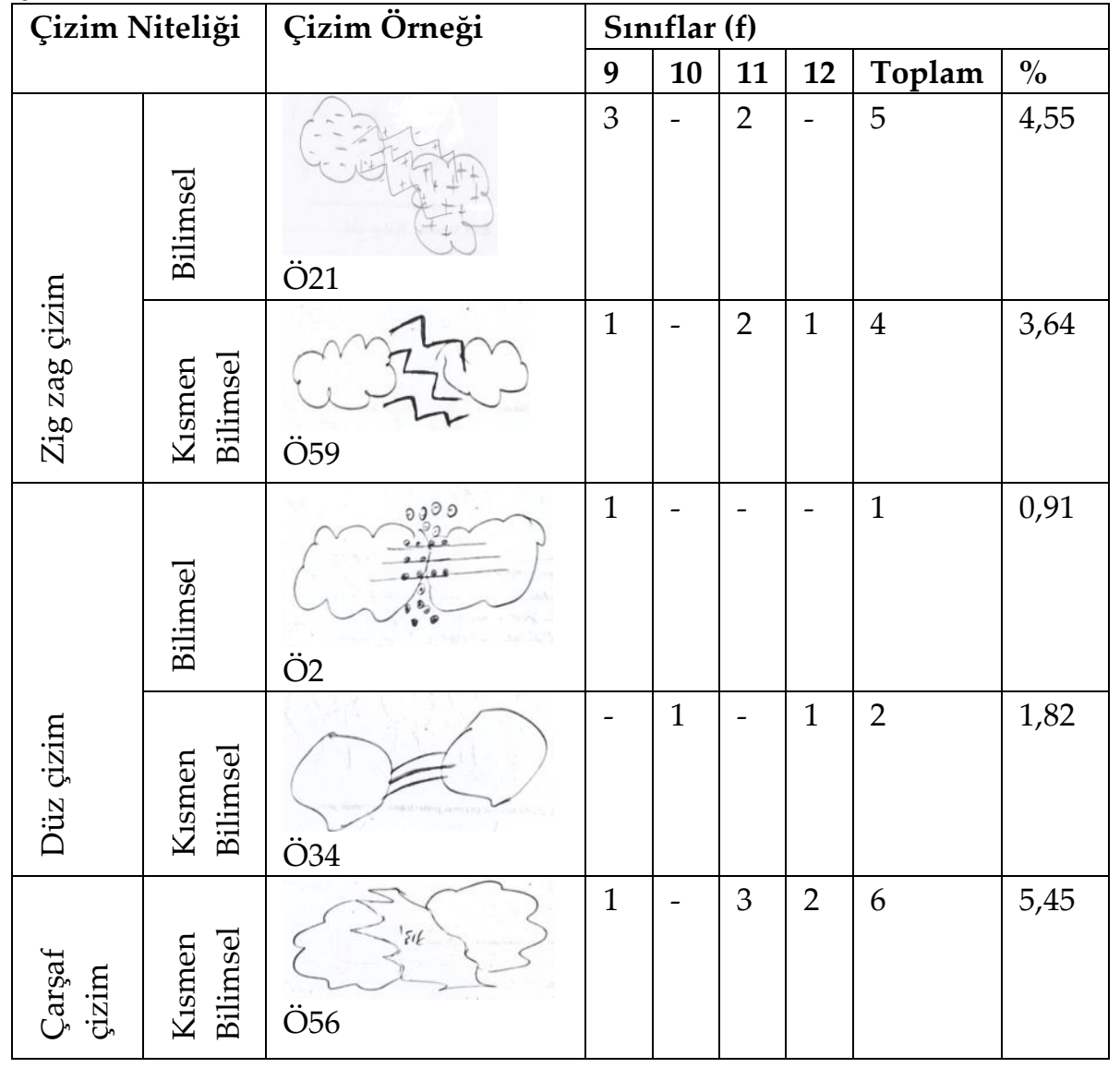




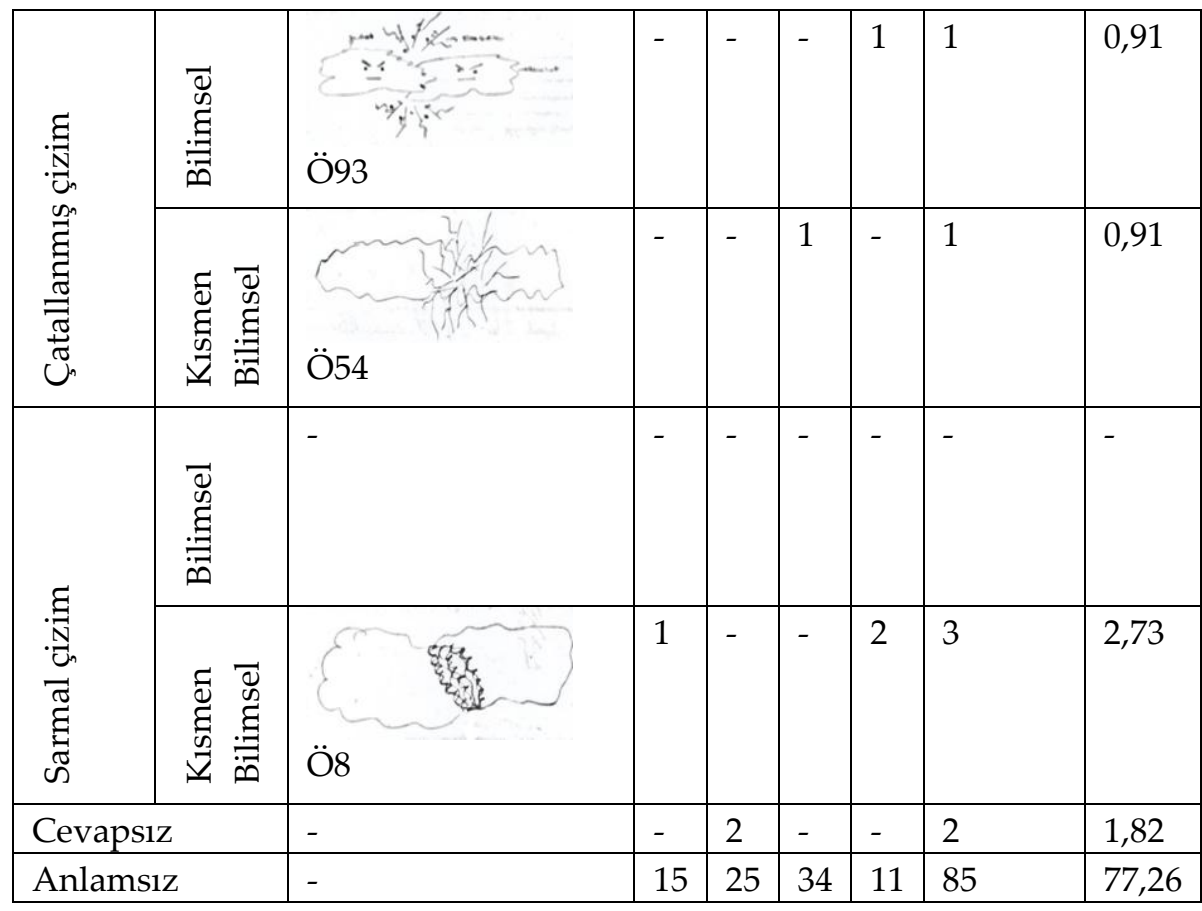

Tablo 2'de görüldüğü gibi öğrencilerin tamamına yakını şimşek çakması sürecinde meydana gelen etkileşim için bilimsel nitelikte bir çizim gerçekleştirmemişlerdir. Çizimler incelendiğinde en dikkat çekici çizim öğrencilerin yaklaşık \% 8'i tarafından çizilen 'zig zag çizim' olarak nitelendirilen çizim tipidir.

Öğrencilerin şimşek için verdikleri betimsel ve görsel cevapların karşılaştırılması sonucu ortaya çıkarılan zihinsel modeller Tablo 3'te sunulmuştur.

Tablo 3: Şimşek Kavramına Ait Öğrenci Zihinsel Modellerinin Dağılımı

\begin{tabular}{|c|c|c|c|c|c|c|c|c|}
\hline $\begin{array}{l}\text { Sin } \\
\text { if }\end{array}$ & \multicolumn{2}{|c|}{$\begin{array}{l}\text { Bilimsel } \\
\text { model }\end{array}$} & \multicolumn{3}{|c|}{ Sentez model } & \multicolumn{3}{|c|}{ İlkel model } \\
\hline & $\mathrm{f}$ & $\%$ & $\mathrm{f}$ & & $\%$ & $\mathrm{f}$ & & $\%$ \\
\hline 9 & 4 & \multirow[t]{4}{*}{6,36} & 15 & \multirow[t]{4}{*}{83} & \multirow[t]{4}{*}{75,46} & 3 & \multirow[t]{4}{*}{20} & \multirow[t]{4}{*}{18,18} \\
\hline 10 & - & & 22 & & & 6 & & \\
\hline 11 & 2 & & 33 & & & 7 & & \\
\hline 12 & 1 & & 13 & & & 4 & & \\
\hline
\end{tabular}


Tablo 3'te görüldüğü gibi şimşek kavramıyla ilgili öğrencilerin çok azı (\% 6) bilimsel, yaklaşık altıda biri ilkel (\% 18) ve yarısından fazlası sentez (\% 75) modele sahiptir. Öğrencilerin sınıflar bazında bu çalışmaya katılım oranları dikkate alındığında Tablo 3'e göre en başarılı 9. sınıflar olarak dikkat çekmektedir.

Öğrencilerin Yıldırımla Illgili Başarı Durumları ve Zihinsel Modelleri

Öğrencilerin yıldırım kavramıla ilgili algılamalarına yönelik elde edilen bulgular (veri toplama aracının üçüncü sorusu doğrultusunda) Tablo $4^{\prime}$ de sunulmuştur.

Tablo 4: Yıldırım Kavramı İçin Betimsel Öğrenci Cevapları Değerlendirmesi

\begin{tabular}{|l|l|l|l|l|l|l|}
\hline \multirow{2}{*}{ Kodlar } & \multicolumn{6}{|l|}{ Sinıflar (f) } \\
\cline { 2 - 8 } & $\mathbf{9}$ & $\mathbf{1 0}$ & $\mathbf{1 1}$ & $\mathbf{1 2}$ & Toplam & \% \\
\hline Bilimsel Doğru & 6 & 2 & 2 & - & 10 & 9,09 \\
\hline $\begin{array}{l}\text { Kismen Doğru } \\
\text { (Yanlışsız) }\end{array}$ & 11 & 16 & 26 & 13 & 66 & 60 \\
\hline $\begin{array}{l}\text { Kismen Doğru } \\
\text { (Yanlışlı) }\end{array}$ & 1 & 3 & 4 & 4 & 12 & 10,91 \\
\hline Yanlış & 2 & 5 & 8 & 1 & 16 & 14,55 \\
\hline Cevapsız & 2 & 2 & 2 & - & 6 & 5,45 \\
\hline
\end{tabular}

Tablo 4'te görüldüğü gibi yıldırım kavramının ne olduğuyla ilgili soruya verilen öğrenci cevaplarının büyük bir çoğunluğu (\% 60) kısmen doğru(yanlışsız) içeriğe/içeriklere sahiptir. Kısmen doğru (yanlışsız) kategorisinde değerlendirilen bazı öğrencilere ait örnek cevaplar "elektrik yükünün yeryüzüne düşmesi (Ö90)" ve "gökten düşen bir şey (Ö48)" şeklindedir. Öğrencilerin yaklaşık \%11'i kısmen doğru (yanlışlı) cevaplar vermiş̧ olduğu görülmektedir. Bazı öğrencilerin verdiği örnek cevaplar; "bulutların çarpışmasıyla oluşan elektrik sayısı (Ö26)" ve "elektrik yüklü şeylerin çarpıp 1şık çıkarması (Ö89)" şeklindedir. Öğrenci cevaplarının çok az bir kısmı (\% 9) bilimsel doğru kategorisinde yer almaktadır. Bu kısımda değerlendirilen "yüklü bulutların yüklerini toprakla etkileşime geçip boşaltmasıdır (Ö12)", "elektrik yüklü bulutların yeryüzü ile etkileşimi sonucu, sahip oldukları yüklerin boşalması olayı ( Ö32)", "bulutların 
sürtünmesi ile oluşan elektrik akımının yeryüzüne düşmesi (Ö18)" ve " yerle gök arasındaki elektriklenme (Ö5)" bazı öğrencilere ait örnek cevaplardır.

Öğrencilerin yıldırım düşmesi sürecinde meydana gelen etkileşimle ilgili olarak zihinlerinde oluşan görsellerle ilgili elde edilen bulgular (veri toplama aracının dördüncü sorusu doğrultusunda) Tablo 5'de sunulmuştur.

Tablo 5'de görüldüğü gibi öğrencilerin büyük bir çoğunluğu bilimsel nitelikte çizim gerçekleştirememiştir. Öğrenci çizimlerinin niteliği şimşek için gerçekleştirilen çizimlerle benzerlik göstermektedir. Yine zig zag çizim yıldırım sürecinde meydana gelen etkileşimler için en çok çizilen (\% 48) öğrenci çizimidir.

Tablo 5: Yıldırım Düşmesi Sürecinde Meydan Gelen Etkileşimle İlgili Öğrenci Çizimlerinin Nitelikleri

\begin{tabular}{|c|c|c|c|c|c|c|c|c|}
\hline \multirow{2}{*}{\multicolumn{2}{|c|}{ Çizim Niteliği }} & \multirow{3}{*}{ Çizim Örneği } & \multicolumn{6}{|c|}{ Sinıflar (f) } \\
\hline & & & 9 & 10 & 11 & 12 & Toplam & $\%$ \\
\hline \multirow[b]{2}{*}{ 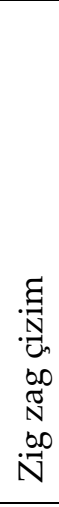 } & 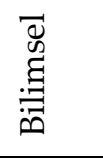 & & & & & & & \\
\hline & 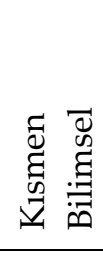 & Ö80 & 7 & 10 & 20 & 7 & 44 & 40 \\
\hline \multirow[b]{2}{*}{ 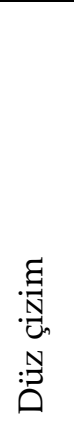 } & 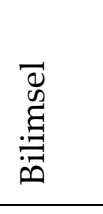 & $\begin{array}{c}1 \\
1 \\
\text { Ö3 }\end{array}$ & 1 & - & - & - & 1 & 0,91 \\
\hline & 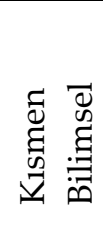 & $\begin{array}{c}8 \\
\text { Ö36 }\end{array}$ & 1 & 7 & 11 & 1 & 20 & 18,18 \\
\hline
\end{tabular}


Uşak Üniversitesi Sosyal Bilimler Dergisi

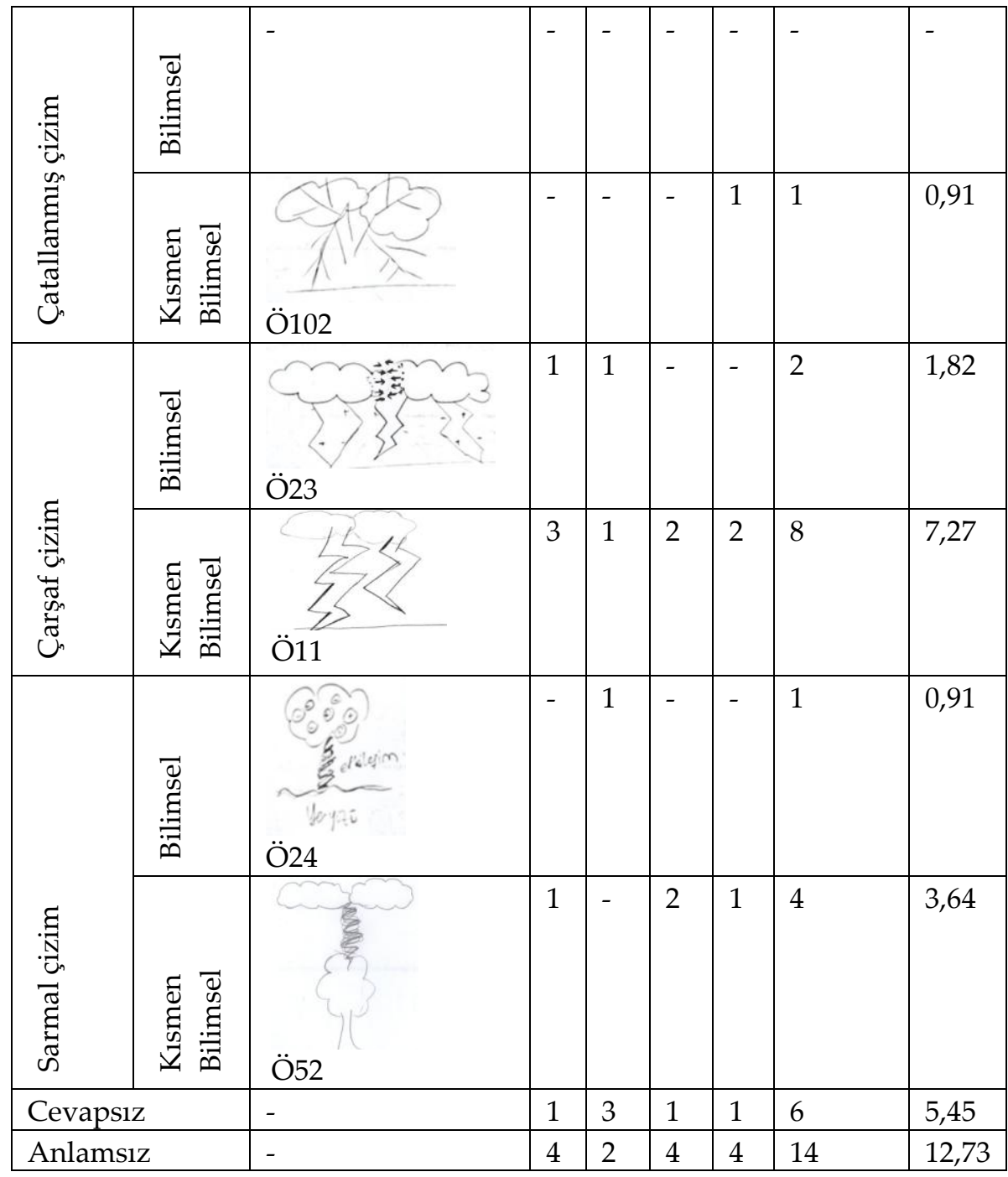

Öğrencilerin yıldırım için verdikleri betimsel ve görsel cevapların karşılaştııılması sonucu ortaya çıkan zihinsel modeller Tablo 6'da sunulmuştur.

Tablo 6: Yıldırım Kavramına Ait Öğrenci Zihinsel Modellerinin Dağılımı

\begin{tabular}{|l|l|l|l|l|l|l|}
\hline Sinıf & \multicolumn{2}{|l|}{$\begin{array}{l}\text { Bilimsel } \\
\text { model }\end{array}$} & \multicolumn{2}{|l|}{ Sentez model } & \multicolumn{2}{l|}{ Ilkel model } \\
\hline & $\mathrm{f}$ & $\%$ & $\mathrm{f}$ & $\%$ & $\mathrm{f}$ & $\%$ \\
\hline
\end{tabular}




\begin{tabular}{|c|c|c|c|c|c|c|c|c|c|}
\hline 9 & 5 & \multirow{4}{*}{9} & \multirow{4}{*}{8,18} & 13 & & \multirow{4}{*}{70,91} & 4 & \multirow{4}{*}{23} & \multirow{4}{*}{20,91} \\
\hline 10 & 2 & & & 22 & 70 & & 4 & & \\
\hline 11 & 1 & & & 31 & 70 & & 10 & & \\
\hline 12 & 1 & & & 12 & & & 5 & & \\
\hline
\end{tabular}

Tablo 6'da görüldüğü gibi yıldırım kavramıyla ilgili öğrencilerin çok azı (\% 8) bilimsel, yaklaşık beşte biri ilkel (\% 20) ve yarısından fazlası sentez (\% 70) modele sahiptir. Öğrencilerin sınıflar bazında bu çalışmaya katılım oranları dikkate alındığında dokuzuncu sınıflar en başarılı sınıf seviyesi olarak dikkat çekmektedir.

Öğrencilerin Elektriklenmeyle İlgili Başarı Durumları ve Zihinsel Modelleri

Öğrencilerin elektriklenme kavramıla ilgili algılamalarına yönelik elde edilen bulgular (veri toplama aracının beşinci sorusu doğrultusunda) Tablo 7'de sunulmuştur.

Tablo 7: Elektriklenme Kavramı İçin Betimsel Öğrenci Cevapları Değerlendirmesi

\begin{tabular}{|l|l|l|l|l|l|l|}
\hline \multirow{2}{*}{ Kodlar } & \multicolumn{6}{|l|}{ Sinıflar (f) } \\
\cline { 2 - 7 } & $\mathbf{9}$ & $\mathbf{1 0}$ & $\mathbf{1 1}$ & $\mathbf{1 2}$ & Toplam & $\mathbf{\%}$ \\
\hline Bilimsel Doğru & 3 & 2 & 5 & - & 10 & 9,09 \\
\hline $\begin{array}{l}\text { Kismen Doğru } \\
\text { (Yanlışsız) }\end{array}$ & 11 & 14 & 25 & 3 & 53 & 48,18 \\
\hline Kısmen Doğru (Yanlışlı) & 6 & 2 & - & - & 8 & 7,27 \\
\hline Yanlış & 1 & 7 & 11 & 15 & 34 & 30,91 \\
\hline Cevapsız & 1 & 3 & 1 & - & 5 & 4,55 \\
\hline
\end{tabular}

Tablo 7'de görüldüğü gibi elektriklenmenin ne olduğuyla ilgili verilen öğrenci cevaplarının çok azı bilimsel niteliktedir. Öğrencilerin yarısına yakını (\% 48) kısmen doğru(yanlışsız) cevaplar verirken, çok az bir kısmı(\% 7) kısmen doğru(yanlışlı) cevaplar vermişlerdir. Kısmen doğru ancak yanlışsız kategorisinde değerlendirilen bazı öğrencilere ait örnek cevaplar "negatif ve pozitif yüklerin etkileşime girmesi (Ö2)" ve "zıt yüklerin etkileşimi (Ö77)" şeklindedir. Kısmen doğru ancak yanlışlı kategorisinde değerlendirilen bazı öğrencilere ait örnek cevaplar ise "iyonların sürtüşmesi sonucu - yüklü iyonların oluşmasına elektriklenme denir (Ö19)" ve "+ ile yani zıt kutupların yan yana geliş sırası (Ö21)" şeklindedir. Bilimsel içerik 
kategorisinde değerlendirilen "+ ve - yüklerin birbirleriyle etkileşimi sonucu + veya - ile yüklenmelerine denir (Ö14)", "+ ve - yüklerin aralarında oluşan çekim kuvveti (Ö23)", "+ ve - yüklerin bir araya gelip kendilerini çekmeleri (Ö46)" ve "iki zit yüklü maddelerin birbiri ile etkileşiminden kaynaklanır. Aralarındaki çekim kuvveti (Ö53)" bazı öğrencilere ait örnek cevaplardır.

Öğrencilerin elektriklenme olayı sürecinde meydana gelen etkileşimle ilgili olarak zihinlerinde oluşan görsellerle ilgili elde edilen bulgular (veri toplama aracının altıncı sorusu doğrulusunda) Tablo 8'de sunulmuştur.

Tablo 8: Elektriklenme Olayı Sürecinde Meydana Gelen Etkileşimle İlgili Öğrenci Çizimlerinin Nitelikleri

\begin{tabular}{|c|c|c|c|c|c|c|c|c|}
\hline \multirow{2}{*}{\multicolumn{2}{|c|}{$\begin{array}{l}\text { Çizim } \\
\text { Niteliği }\end{array}$}} & \multirow{2}{*}{ Çizim Örneği } & \multicolumn{6}{|c|}{ Sinıflar (f) } \\
\hline & & & 9 & 10 & 11 & 12 & Toplam & $\%$ \\
\hline \multirow{2}{*}{ 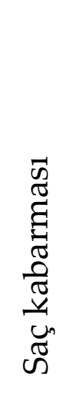 } & 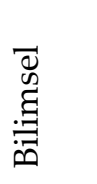 & $\begin{array}{l}\text { Ö5 } \\
\text { Ö }\end{array}$ & 1 & - & - & - & 1 & 0,91 \\
\hline & 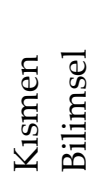 & Ö6 & 2 & 1 & 2 & - & 5 & 4,55 \\
\hline \multirow[b]{2}{*}{ 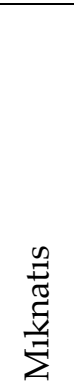 } & 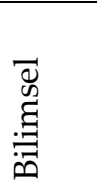 & Ö13 & 1 & 1 & 2 & 1 & 5 & 4,55 \\
\hline & 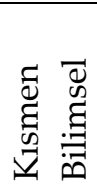 & $\underset{\text { Ö77 }}{\sqrt{N}}$ & - & - & 1 & - & 1 & 0,91 \\
\hline
\end{tabular}




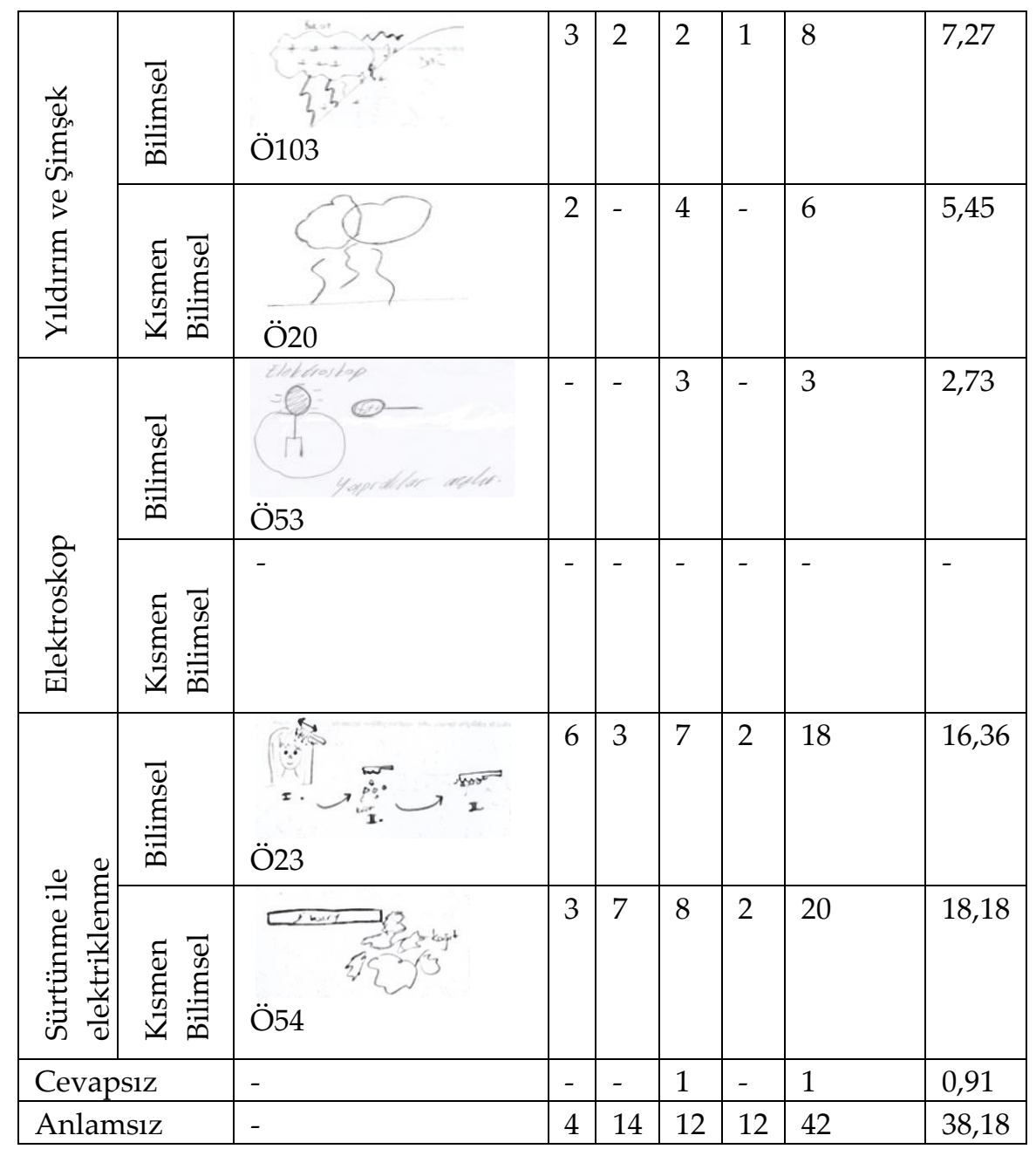

Tablo 8'de görüldüğü gibi elektriklenme olayı sürecinde meydana gelen etkileşimle ilgili görselleri çoğunlukla bilimsel nitelik taşımamaktadır. Dikkat çeken bulgular, örnek çizimlerde de görüldüğü gibi, bazı öğrencilerin (\% 34) sürtünmeyle elektriklenmeyi, bazı öğrencilerinse (\% 12) yıldırım ve şimşek olayını gösteren çizimler ortaya koymasıdır.

Öğrencilerin elektriklenme için verdikleri betimsel ve görsel cevapların karşılaştırılması sonucu ortaya çıkarılan zihinsel modeller Tablo 9'da sunulmuştur.

Tablo 9: Elektriklenme Kavramına Ait Öğrenci Zihinsel Modellerinin Dağılımı 
Uşak Üniversitesi Sosyal Bilimler Dergisi

M. A. KURNAZ, F. TARAKÇI, A. SAYDAM, M. PEKTAŞ

\begin{tabular}{|c|c|c|c|c|c|c|c|c|c|}
\hline Sinıf & \multicolumn{3}{|c|}{$\begin{array}{l}\text { Bilimsel } \\
\text { model }\end{array}$} & \multicolumn{3}{|c|}{ Sentez model } & \multicolumn{3}{|c|}{ İlkel model } \\
\hline & $\mathrm{f}$ & & $\%$ & $\mathrm{f}$ & & $\%$ & $\mathrm{f}$ & & $\%$ \\
\hline 9 & 8 & \multirow{4}{*}{30} & \multirow{4}{*}{$\begin{array}{l}27,2 \\
7\end{array}$} & 13 & \multirow{4}{*}{44} & \multirow{4}{*}{40} & 1 & \multirow{4}{*}{36} & \multirow{4}{*}{32,73} \\
\hline 10 & 5 & & & 14 & & & 9 & & \\
\hline 11 & 14 & & & 16 & & & 12 & & \\
\hline 12 & 3 & & & 1 & & & 14 & & \\
\hline
\end{tabular}

Tablo 9'da görüldüğü gibi elektriklenme kavramlarıyla ilgili az sayıda öğrenci (\% 27) bilimsel, yaklaşık üçte biri ilkel (\% 32) ve yarısına yakını sentez (\% 40) modele sahiptir. Öğrencilerin sınıflar bazında çalışmaya katılım oranları göz önüne alındığında dokuzuncu sınıflar en başarılı sınıf seviyesi olarak dikkat çekmektedir.

Öğrencilerin elektriklenme, şimşek ve yıldırım için belirlenen zihinsel modellerinin karşılaştırılması sonucu ortaya çıan genel zihinsel modeller Tablo 10'da sunulmuştur.

Tablo 10: Konuyla İlgili Öğrencilerin Genel Zihinsel Modellerinin Dă̆ı̆lımı

\begin{tabular}{|c|c|c|c|c|c|c|c|c|c|}
\hline $\begin{array}{l}\text { Sin } \\
\text { if }\end{array}$ & \multicolumn{3}{|c|}{$\begin{array}{l}\text { Bilimsel } \\
\text { model }\end{array}$} & \multicolumn{3}{|c|}{ Sentez model } & \multicolumn{3}{|c|}{ İlkel model } \\
\hline & $f$ & & $\%$ & $\mathrm{f}$ & & $\%$ & $\mathrm{f}$ & & $\%$ \\
\hline 9 & 2 & \multirow{4}{*}{4} & \multirow{4}{*}{3,63} & 20 & \multirow{4}{*}{103} & \multirow{4}{*}{93,64} & - & \multirow{4}{*}{3} & \multirow{4}{*}{2,73} \\
\hline 10 & - & & & 28 & & & - & & \\
\hline 11 & 1 & & & 40 & & & 1 & & \\
\hline 12 & 1 & & & 15 & & & 2 & & \\
\hline
\end{tabular}

Tablo 10'da görüldüğü gibi elektriklenme, şimşek ve yıldırım kavramlarıyla ilgili sadece dört öğrenci (\% 3) bilimsel zihinsel modele, üç öğrenci (\% 2) ilkel zihinsel modele ve büyük bir çoğunluğuysa (\% 93) sentez zihinsel modele sahiptir.

\section{Tartışma ve Sonuç}

$\mathrm{Bu}$ çalışmada, lise öğrencilerinin şimşek, yıldırım ve elektriklenme kavramlarıyla ilgili zihinsel modelleri incelenmiştir. Çalışma kapsamında ortaya çıarılan zihinsel modeller öğrencilere yöneltilen sorularla ve belirlenen analiz yöntemiyle sinırlıdır. 
Elde edilen betimsel bulgular incelendiğinde şimşek ve yıldırım kavramları için öğrencilerin yaklaşık dörtte birinin, elektriklenme için yarıya yakınının yanlışlı bilgilere sahip olduğu anlaşılmaktadır. Elde edilen bu bulgular Ayvacı, Özsevgeç ve Cerrah (2004) ve Aydın ve Özkara'nın (2011) sonuçlarıyla örtüşmektedir. Aydın ve Özkara öğrencilerin özellikle, bu çalışmada olduğu gibi, doğal elektriklenme konusundaki yanılgıları olduğu ön plana çıkarmaktadır. Buradan öğrencilerin elektriklenme ile ilgili algılamalarının yetersiz olduğu ve şimşek ve yıldırım kavramları arasındaki ilişkilendirmeyi yapamadıkları ifade edilebilir. Nitekim, Ayvacı, Özsevgeç ve Cerrah (2004) tarafından ileri sürülen öğrenci görüşleri de elektriklenmeyle ilgili bilgi eksikliğinin şimşek ve yıldırım kavramlarının algılanmasında olumsuzluk oluşturduğu anlaşılmaktadır. Ayrıca bu konu alanında yapılmış olan diğer iki çalışmanın aksine (Ayvacı, Özsevgeç \& Cerrah, 2004; Aydın \& Özkara, 2011) bu çalışmada az sayıda öğrenci şimşek ve yıldırım kavramlarını birbirlerinin yerine kullanmışlardır.

Elde edilen görsel bulgular incelendiğinde öğrencilerin şimşek ve yıldırımla ilgili çizimleri zig zag çizim, düz çizim, çarşaf çizim, çatallanmış çizim ve sarmal çizim şeklinde sınıflanmaktadır. Elektriklenme için çizilen görseller saç kabarması, mıknatıs, yıldırım ve şimşek, elektroskop, sürtünme ile elektriklenme kategorilerindedir. Elektriklenme ve şimşekle ilgili çizimler çoğunlukla bilimsellikten uzakken yıldırımla ilgili çizimler kısmen bilimsel öğeleri de kapsayan niteliktedir. Şimşek çizimlerinde öğrenciler çoğunlukla yük geçişlerini gösterememiş olmaları öğrencilerin elektriklenme konusundaki başarısızlığından kaynaklanıyor olabilir. Öğrencilerin şimşek, yıldırım ve elektriklenme konularındaki görsel algılamalarına yönelik bir çalışmaya rastlanmamış olsa da Ayvacı, Özsevgeç ve Cerrah (2004) ve Aydın ve Özkara (2011) çalışmalarında toplanan betimsel bulgular bu çalışmada ulaşılan görsel bulguları desteklemektedir.

Öğrencilerin betimsel ve görsel bulgularından hareketle ulaşılan zihinsel modelleri irdelendiğinde elektriklenme, şimşek ve yıldırım kavramları için öğrencilerin çoğunlukla sentez modele sahip olduğu anlaşılmaktadır. Bu durum öğrencilerin okul bilgisinden edinimleri olduğunu ancak bunun yeterli oranda olmadığını göstermektedir (Vosniadou \& Brewer, 1994; Vosniadou \& Brewer, 1992). Diğer bir ifadeyle öğrenciler okul bilgisiyle (yanlış/bilimsel olmayan) günlük hayat bilgisini birleştirerek konuyla ilgili zihinsel yapılandırmalarını gerçekleştirmektedir. 
Diğer bir bakış açısıyla okulda verilen bilgiler bilimsel olmayan günlük hayat bilgisini değiştirerek kavramsal öğrenmeyi tamamlama da yeterli olmamıştır.

Özetle, öğrenciler elektriklenme, şimşek ve yıldırım kavramları için bilimsel olmayan bilgilere sahiptirler ve zihinsel modelleri sentez zihinsel model seviyesindedir. Bu anlamda öğrencilerin bilimsel zihinsel modellere sahip olabilmeleri için öğrenme ortamlarında üç kavramın birbiriyle ilişkili bir bütünlük içinde sunulması önerilmektedir. Bu süreçte özellikle öğrenci zihinsel modellerinin yapılanmasına yardımcı olacak görsel çizimlere yer verilmesi, üç kavram arasındaki ilişki farklılıkları yansıtacak anlam çözümleme tablolarının kullanılması ve olası yanlış algılamalara yönelik kavramsal değişim metinlerinin kullanılması önerilmektedir.

\section{Kaynaklar}

ATEŞ, S. (2005). The effects of learning cycle on college studentse understanding of different aspects in resistive DC circuits. Electronic Journal of Science Education, 9(4), 1-20.

AYDIN, M. \& ÖZKARA, D.(2011). Fen bilgisi öğretmenliği öğrencilerinin atmosferde meydana gelen doğal elektriklenme konusundaki kavram yanılgiları ve bilgi eksiklerinin belirlenmesi. Adryaman Üniversitesi Sosyal Bilimler Enstitüsü Dergisi, 4 (6),11-20.

AYDOGAN, S., GÜMÜS , B. \& GÜLÇIÇEK, Ç., (2003). Isı ve sıcaklık konusunda kavram yanılgıları. G.Ü. Gazi Egitim Fakültesi Dergisi, 23(2), 111-124.

AYVACI, H.Ş., ÖZSEVGEÇ, T. \& CERRAH, L. (2004). "Yıldırım kavramının farklı yaş grubundaki öğrencilerde gelişimi". Kastamonu Ĕ̆itim Fakültesi Dergisi, 12(2), $351 \quad-360$.

BORGES, A.T. \& GİLBERT, J.K. (1999). Mental models of electricity. International Journal of Science Education, 21(1), 95-117.

BUCKLEY, B. C., GOBERT, J. D., and CHRISTIE, M. T. (2002). Model-based Teaching and Learning with Hypermodels: What do they learn? How do they learn? How do we know?. Presented as part of the symposium Hypermodel Research in Theory and Practice. April 2002, American Educational Research Association, New Orleans.

BULUŞ E.K. \& GÜLLÜ, D. (2008). Fifth grade students' misconceptions about heat - temperature and evaporation - boiling. Elementary Education Online, 7(1), 15-27. 
BÜYÜKKASAP, E., DÜZGÜN, B. \& ERTUĞRUL, M. (2001). Lise Öğrencilerinin Işık Hakkındaki Yanlış Kavramları, Milli Ĕ̆gitim Dergisi, 32-35.

ÇALIK, M. \& AYAS, A. (2005). A comparison of level of understanding of grade 8 students and science student teachers related to selected chemistry concepts. Journal of Research in Science Teaching, 42(6), 638667.

ÇEPNI, S. (2012). Araştırma ve Proje Çalışmalarına Giriş (6. Baskı). Trabzon: Celepler Matbaacilik.

DRIVER, R. (1995). Constructivist approaches to science teaching. L. P. Steffe and J. Gale (Ed.), Constructivism in education (385-400). Hillsdale, NJ: Lawrence Erlbaum Associates.

DUIT, R., ve TREAGUST, D. F. (1998). Learning in science - from behaviorism towards social constructivism and beyond. B. J. Fraser and K. G. Tobin (Ed.), International handbook of science education. Great Britain: Kluwer Academic Publishers.

GOBERT, J. D., \& BUCKLEY, B. C. (2000). Introduction to model-based teaching and learning in science education. International Journal of Science Education, 22 (9), 891 - 894.

GRECA, I. M., \& MOREIRA, M. A. (2000). Mental models, conceptual models, and modelling. International Journal of Science Education, 22(1), 1-11.

HANKE, U. (2008). Realizing Model-Based Instruction - The Model of model-based instruction. D. Ifenthaler, P. Pirnay-Dummer and J. M. Spector (Ed.), Understanding Models for Learning and Instruction. Springer Science+Business Media, LLC.

HANKE, U., \& HUBER, E. (2010). Acceptance of Model-Based Instruction among Students in Spanish and Mathematics. J. M. Spector, D. Ifenthaler, P. Isaías, Kinshuk, and D. Sampson (Ed.), Learning and Instruction in the Digital Age. Springer Science+Business Media, LLC.

HESTENES, D. (2006). Notes for a Modeling Theory of Science, Cognition and Instruction. Proceedings of the GIREP conference: Modelling in Physics and Physcis Education.

KELEŞ, E. (2007). Altıncı sımı kuvvet ve hareket ünitesine yönelik beyin temelli öğrenmeye dayal web destekli öğretim materyalinin geliştirilmesi ve etkililiğinin değerlendirilmesi. Yayınlanmamış Doktora Tezi, KTÜ, Fen Bilimleri Enstitüsü, Trabzon. 
KORAY, Ö., ÖZDEMIR, M. \& TATAR, N. (2005). İlköğretim öğrencilerinin birimler hakkında sahip oldukları kavram yanılgıları: kütle ve ağırlık örneği, İlköğretim -Online, 4(2), 24-31.

KURNAZ M. A. (2011). Enerji Konusunda Model Tabanlı Öğrenme Yaklaşımına Göre Tasarlanan Öğrenme Ortamlarının Zihinsel Model Gelişimine Etkisi. Yayınlanmamış Doktora Tezi, Karadeniz Teknik Üniversitesi, Trabzon, Türkiye.

NERSESSIAN, N. J. (1995). Should physicists preach what they practice? Constructive modeling in doing and learning physics. Science $\mathcal{E}$ Education, 4, 203-226.

ÖZMEN, H., DEMIRCİĞLU, G. \& COLL, R. K. (2009). A comparative study of the effects of a concept mapping enhanced laboratory experience on Turkish high school students' understanding of acid-base chemistry, International Journal of Science and Mathematics Education, 7, 124.

SENCAR, S., YILMAZ, E. E., \& ERYILMAZ, A. (2001). High School Students' Misconceptions About Simple Electric Circuits, Hacettepe Üniversitesi Eğitim Fakültesi Dergisi 21, 113-120.

TAYLOR, I., BARKER, M., \& JONES, A. (2003). Promoting mental model building in astronomy education. International Journal of Science Education, 25 (10), 1205-1225.

VOSNIADOU, S., \& BREWER, W. F. (1992). Mental models of the earth: a study of conceptual change in childhood. Cognitive Psychology, 24, 535585.

VOSNIADOU, S., \& BREWER, W. F. (1994). Mental models of the day/night cycle. Cognitive Science, 18, 123-183.

YİN, R. K. (2003). Case Study Research: Design and Methods (3rd Ed.). London: Sage Publications.

YÜRÜK, N. (2007). A case study of one student's metaconceptual process and the changes in her alter-native conceptions of force and motion. Eurasia Journal of Mathematics, Science E Technology Education, 3(4), 305325. 